Publisher policy allows this work to be made available in this repository. Published in Integrating Social and Employment Policies in Europe: Active Inclusion and Challenges for Local Welfare Governance (ed.by Martin Heidenreich and Deborah Rice), copyright Edward Elgar Publishing. The original publication is available at: http://www.eelgar.com/shop/integrating-social-and-employment-policies-in-europe

The only uses of this work permitted are private study or research. 


\section{Personalized activation policies for the long-term unemployed: the role of local governance in the UK}

\section{Vanesa Fuertes}

\section{Ronald McQuaid}

\subsection{Introduction: coordinated activation and localism}

Activation policies, as described in Chapter 2, have been at the core of the UK welfare state since at least the 1990s. There has been a diminishing emphasis on income replacement for working aged benefit recipients and a greater stress on labour market participation, alongside increased conditionality and sanctions (Oakley 2014). The increase of active labour market policies has been mostly characterized by supply-side measures, which have been relatively disconnected from demand-side labour market policies that aim to influence the number and accessibility of jobs for those unemployed. Another important characteristic of the activation trend in the UK has been the widening of the target groups of activation, some with complex and multiple health and other problems.

It is widely argued that in order to be effective, activation policy implementation requires to be flexible, bottom-up, local and with services tailored to the needs and circumstances of each individual (Van Berkel and Borghi 2008, McQuaid and Lindsay 2005): what this volume refers to as multidimensional, multi-stakeholder, and multilevel coordination (see Chapter 2). There are, however, many barriers to coordination such as funding 
regulations, the skills and resources of potential partners, competences boundaries, and administrative arrangements. As a result, policy 'silos' (i.e. agencies operating semi-independently of each other without effective coordination) and a fragmentation of service delivery and accessibility have been characteristic of many activation policies. It has been argued that the proliferation of service providers from the public, private and third sectors, in part as a result of the marketization of public services, has increased such fragmentation but also collaboration efforts between providers (Stewart 2005).

The introduction of a marketized activation scheme in the UK has taken place alongside wider changes to public sector governance, which is increasingly (although not solely) dominated by New Public Management (NPM) characteristics, such as managerialism and treating citizens as customers (Rhodes 1997). While it has been stated that activation requires new forms of governance to transform the paradigm of the welfare state from a sector-based to a multi-sector joined-up, seamless service delivery (Karjalainen 2010, Saikku and Karjalainen 2012), New Public Management has been accused of further exacerbating fragmentation in public service delivery. Therefore present governance models could in fact work against the coordination needs of activation policy. While UK Government labour market policy at the start of the 2010s continued on a path of activation and market-based governance inherited from previous administrations, the Work Programme of 2011 included new opportunities for coordination, and these are a focus of this chapter.

Our question is: can the governance of activation policy, including recent policy and governance changes, achieve a high level of service coordination in 
the UK? In order to answer this question, both the national and the regional/local levels of policy making and implementation have to be analysed; as although national governance frameworks undoubtedly frame and shape local policies and practices, the local level has been recognized as being able to influence the implementation of policy and the delivery of services in its own right (Kazepov 2010, Künzel 2012, Finn 2000). The ability of local actors to shape local implementation and service delivery can result from a number of factors, such as the discretion afforded to the local level, the role of past experiences and traditions (Künzel 2012, McQuaid 2010, Finn 2000, Fuertes and McQuaid 2013b), and the influence of local street-level bureaucrats exercising (low) levels of political power (Lipsky 1980).

In this chapter we analyse the roles of governance structures and local actors in achieving coordination between stakeholders, administrative levels and services from different policy fields in the context of activation policies. This is what has been termed multi-stakeholder, multilevel and multidimensional coordination in Chapter 2. Specifically, we consider the UK's main activation policy for the long-term unemployed since 2011, the Work Programme, and its wider policy context. Our attention focuses on the effects of current governance structures on inter-organizational coordination at the service delivery level because, as Van Berkel et al. (2012) argue, governance reforms affect social policy practices. We ask: does the governance of activation policies affect the achievement of coordination, the practices of organizations and individuals, and the services that are actually offered at the local level? 
The chapter compares Cardiff, Edinburgh and Newcastle, three urban areas reflecting different levels of economic prosperity and different national contexts across the UK. The following section sets out the broad context of the national governance of activation policy. Section 5.3 describes the methods used in the analysis. Section 5.4 focuses on local policy coordination efforts across service areas, administrative levels and organizational actors, while section 5.5 considers the practices of street-level bureaucrats as the final actors in the service delivery chain. The chapter ends with some conclusions.

\subsection{National activation policy and governance in the UK}

In the UK long-term unemployment has increased during the economic crisis from $24 \%$ in 2007 to $36 \%$ in 2013 . The increase in long-term unemployment particularly affected individuals aged 50 and over and to a slightly lesser extent those in the 18 to 24 age group, although total unemployment especially affected the latter group (Figure 5.1).

$<$ Please insert Figure 5.1 - UK unemployment rates (left graph) and long-term unemployment* rates (right graph)>

The number of people receiving Jobseeker's Allowance (JSA) is 1.13 million (this can be a contribution-based benefit for six months or an indefinite incomebased benefit), and 1.99 million are in receipt of Employment and Support Allowance (a benefit for those with limited capability for work because of their sickness or disability) (November 2013) ${ }^{1}$. This section describes the national context for activation policies, focusing on the administrative responsibilities for 
activation, the approach to and governance of activation, and finally the changes introduced with the Work Programme.

\section{Active labour market reforms and administrative responsibilities}

Employment policy is the responsibility of the UK government. The devolved administrations in the UK (the Scottish government, the Welsh assembly, and the Northern Ireland Executive) have responsibilities for a number of policy areas that touch upon employment issues, including skills and education, which are conferred and legally defined by the 'reserved power' in Scotland and by legislative competences in Wales. Devolved administrations are financed mainly by the UK Government through a block grant. Currently they can raise limited self-financed expenditure through limited borrowing and non-domestic rates and in Scotland through council taxes and (unused) powers to raise small amounts of income tax. Devolved funds can be invested in employability services for unemployed people. For example, in each of the three cities studied, the devolved administrations and local governments are offering employment services either by public provision or contracting-out, for instance through grants, negotiation or (in many cases) competitive tender to the public, private and third sector. In Edinburgh and Cardiff, Scottish and Welsh devolved employability programmes are in place respectively.

Usually individuals who are unemployed or economically inactive are entitled to income transfers (i.e. benefits). Those who receive income-based rather than contribution-based Jobseeker's Allowance are required to participate in activation measures. Those who receive contribution-based or

income-based Employment Support Allowance after a Work Capability 
Assessment have different activation requirements, depending on whether they are assigned to the Support Group or the Work Related Activity Group. Individuals out of work and responsible for a child under the age of five receive Income Support and are not mandated to participate in activation measures; the same applies to carers who receive Carers Allowance.

UK active labour market responsibilities rest with the Department for Work and Pensions (DWP), and are made up of different types of initiatives: for the short-term unemployed (those age 25 and over that have been unemployment less than 12 months, and those under 25 years-old that have been unemployed less than nine months) there are 'work-first' services mostly focused on job search support; while for the long-term unemployed, programmes can include other support such as placements and vocational training. Activation services for the short-term unemployed are generally provided by Jobcentre Plus (the UK Public Employment Service) and external providers contracted by the DWP. Activation services for the long-term unemployed tend to be provided by contracted-out providers; since 2011, the marketized Work Programme has been the core activation initiative for this group and a few other specific claimant groups (see below). UK level provision often focuses on welfare-to-work and on achieving outflows from benefits, while participation in local and devolved employability initiatives is voluntary and tends to focus more on developing skills, raising employability for particular groups and tackling barriers to employment.

The activation trend in the UK has been characterized by a proliferation of active labour market measures, the increasing compulsion of participation, 
and the conditionality of receiving income benefits on this participation, including the imposition of benefits sanctions (Oakley 2014). The Labour administration (1997-2010) arguably favoured labour market deregulation and supply-side measures over demand-side state interventions in order to achieve economic growth (Taylor-Gooby et al. 2004). These initiatives were often targeted at specific groups of benefit claimants such as lone parents or young people, for example various New Deals that ended in 2010 (Stafford and Kellard 2007). The more generic Flexible New Deal (Vegeris et al. 2010) was followed by the introduction of the Work Programme in 2011. Other supply-side policies include: 'making work pay' measures such as the Working Tax Credit (including the Child Tax Credit that partly aims to help with childcare cost) for people in lower-paid jobs (a form of 'negative income tax'); the introduction of benefit entitlement limits such as the recent benefit 'cap'; and changes to income benefits such as the Universal Credit, a single benefit that will eventually replace a number of current benefits (i.e. income-based Jobseeker's Allowance, income-related Employment and Support Allowance, Income Support, Child Tax Credit, Working Tax Credit and Housing Benefit) with the stated aim of simplifying out-of-work benefits and making them more workfriendly. Specific direct demand-side labour market policies, which aim to influence the number and accessibility of jobs for those unemployed such as salary or tax incentives for employers, have been relatively limited. National aggregate demand policies and regional demand-side policies based on development agencies do exist, but generally do not directly focus on lower level jobs suitable for disadvantaged job seekers. 
Another important characteristic of the activation trend in the UK has been the widening of groups targeted by activation measures. This has been achieved by changes to the benefit entitlement rules, initiated since 2008 and continued during the 2010-15 Coalition government. These have affected those people unemployed with dependent children and receiving Income Support or those with health issues and receiving the now extinct Incapacity Benefit (as it was transformed into the current Employment and Support Allowance). For the former group, entitlement to receive Income Support is determined by the age of their youngest child and this age gradually fell from 16 to 5 years old, at which time claimants move to Jobseeker's Allowance, which requires them to actively seek and accept employment. For the latter group and any new illhealth related benefit claimants, a Work Capability Assessment was introduced, and everyone claiming Incapacity Benefit was reassessed and either transferred to Jobseeker's Allowance or to Employment and Support Allowance. ESA claimants assigned to the Work Related Activity Group are required to take part in some activation while those assigned to the Support Group are not required to actively seek work, although they are regularly monitored for changes in their health status. For those claiming benefits who are capable of undertaking some form of work, activation has meant a greater number of initiatives and compulsion to find employment through the threat of sanctions (Lindsay and Dutton 2012).

The 2010-15 UK Coalition Government largely continued, and in some cases accelerated or expanded, the previous Labour administration's labour market policy approaches. This implied the continuation and expansion of 
changes to income benefit entitlement rules; a new "three strikes and you're out" sanctions regime with escalating penalties for non-compliance with activation measures ${ }^{2}$; a new income benefit that amalgamates a number of other benefits; and the introduction of 'Get Britain Working' measures, the majority of which are supply-side welfare-to-work measures such as work experience, training, and job brokering, with few demand-side interventions such as wage subsidies and incentive payments.

\section{The governance of activation}

With an increase in groups with multiple and complex work barriers participating in activation, services need to account for the heterogeneity and individual needs of the unemployed (McQuaid and Lindsay 2005, Lindsay and McQuaid 2008) and of the labour market (Eichhorst et al. 2008). This requires that activation policies go beyond the classical job-search focus, and include additional social services (delivered by various providers) which in some cases are the remit of other policy areas (such as education and skills, mental and physical, childcare, drug and alcohol rehabilitation, etc.). Therefore coordination between policy dimensions, service providers and in some cases administrative/territorial levels (e.g. national and local co-ordination) may be needed.

Local implementation for those not covered by the Work Programme is organized by Jobcentre Plus, whose role includes providing benefits, basic jobmatching services for the working-age short-term unemployed, and helping employers to fill their vacancies (House of Commons Work and Pensions Committee 2007). Jobcentre Plus employment services and processes are 
prescribed centrally with very little local discretion on provision and with business-type managerial models (Zimmermann and Fuertes 2014). This can be seen as an example of 'procedural' governance that following Considine and Lewis (2003) is characterized by the government designing and implementing policies. However, characteristics of Considine and Lewis's 'corporate' form of governance can be also discerned in the business-type managerial models for providing employment services that have been common in service delivery since at least the 1980s, such as performance measurement, benchmarking, and auditing (cf. Considine and Lewis 2003, Fuertes et al. 2014). Following Ehrler's (2012) typology, the UK's activation governance model would be an example of 'procedural' New Public Management, which is characterized by high performance measurement systems, low contract steering and low operational discretion on the part of the implementing agencies.

Services that are not provided directly by Jobcentre Plus, particularly services for the long-term unemployed or other specific claimant groups, are contracted-out by the Department for Work and Pensions to private or thirdsector organizations mostly through 'market' governance (Considine and Lewis 2003) or 'centralised' New Public Management governance (Ehrler 2012). Under such governance arrangements, providers' discretion over service goals and processes is overall limited, with competition and performance-based payment systems being key features of these contracts. In a few policy initiatives, 'network' governance (Considine and Lewis 2003) features can be seen, where government's role is that of negotiating and brokering interests among actors that come together in collaborative structures and with shared 
leadership. A case in point is the pilot phase of Pathways to Work, a national initiative aimed at supporting those receiving Incapacity Benefit through workfocused interviews and a condition management programme.

Market governance characteristics are particularly prominent in the UK system, as labour market initiatives, especially for the long-term unemployed, are increasingly delivered by external contractors (as illustrated by the Work Programme). Marketization has been heralded as the way to achieve efficiency and effectiveness despite mixed evidence on those claims (Davies 2010, Hudson et al. 2010, National Audit Office 2006, Hasluck and Green 2007). In fact, marketization has been accused of creating overcrowded and fragmented service delivery. In order to achieve what seems to be expected of marketization (i.e. efficiency and responsiveness to citizens' preferences), providers would need to have discretion around the services offered, just as service users would need to have a choice over service provision. However, this has not been the case in the UK were service users do not have a choice of provider and often the discretion of providers is limited (Zimmermann et al. 2014). Since 2012, the UK model of marketization is underpinned by the Framework for the Provision of Employment Related Support Services (DWP nd a). The Work Programme is the first contract to be called-off the Framework and is characterized by the following governance mechanisms: control of providers primarily based on cost, total provider discretion over services, and no client choice (Zimmermann et al. 2014). Due to the Work Programme being the main activation policy for the long-term unemployed (and some other groups) in the UK, and also because the programme represents a relatively new way of co- 
ordinating stakeholders and activities, it is the main example of UK activation policy used in this chapter.

\section{A national activation policy for the long-term unemployed: the Work Programme}

The Work Programme was launched in June 2011 and is one of the 'Get Britain Working' initiatives that replaced a number of previous welfare-to-work programmes (in particular, the Flexible New Deal and Pathways to Work). It is the UK's labour market policy for the long-term unemployed, and it is mandatory for those classified as long-term unemployed, individuals receiving Employment Support Allowance in the Work Related Activity Group (when close to being fit for work) and a number of specific disadvantaged groups (e.g. those leaving prison or seriously disadvantaged recipients of Jobseekers Allowance). Also individuals who have recently received Incapacity Benefit can be required to take part in the Work Programme after 3 months. On-going changes to the welfare system may change these groups slightly. Other benefit recipients can voluntarily be referred to the Work Programme but once on the programme, participation becomes obligatory and, similarly to those mandated, failing to comply with mandatory activities is likely to result in benefit sanctions. The Work Programme is mandatory for up to two years and sanctions are imposed by Jobcentre Plus for non-participation (Fuertes and McQuaid 2013c). Referrals of clients to prime providers are carried out by Jobcentre Plus on a systematic basis, with the same number assigned to each prime provider in a given area. However, the prime provider with better results is allocated an increased market share of clients over time. 
The Work Programme follows the marketization trend of previous welfare-to-work initiatives. Nevertheless, the process has been novel to some extent, due to the requirement for organizations tendering to have no less than a $£ 20$ million annual turnover. Eighteen companies were contracted by the Department for Work and Pensions to deliver the Work Programme in the UK, which has been divided into 18 contract areas (with each area having at least two companies). These 'prime provider' companies (from now on labelled 'primes') hold contracts in one or more contract areas and are in competition with one or - in four areas - two other prime providers. Due to this requirement, many private, public and especially third sector organizations such as voluntary, charitable and not-for profit organizations were unable to compete in the tendering process, and it has been argued that this could contribute to a concentration of large multi-national organizations in the long-term provision of services, creating something close to an oligopoly at the regional level (Fuertes et al. 2014).

Similar to other national initiatives, payment is by results, although the criterion to draw full payment includes a sustainability requirement (with payments rising the longer a participant remains in employment). There is also a clear differentiation in payments according to age, the length of unemployment, and the type of benefit a client receives. Thus, prime providers will receive a minimum total amount of $£ 3,700$ for a young person in Jobseeker's Allowance to a maximum total of $£ 13,700$ for those receiving Employment and Support Allowance in the Support Group, for example (Fuertes and McQuaid 2013c). According to the Department for Work and 
Pensions, the Work Programme aims "to support people at risk of long term unemployment into sustainable employment. Work Programme providers are paid primarily for the results they achieve and they will be paid more for supporting people who are harder to help" (DWP 2012). However, while participants from harder to help groups generate higher payments to the service contractor so as to explicitly avoid 'creaming' and 'parking' issues, this appears to have been ineffective, as our study and a recent evaluation of the Work Programme (Newton et al. 2012) indicate, and as the insignificant movement of people with disabilities into employment suggests.

The Department for Work and Pensions places no procedural requirements on primes over service delivery other than a minimum service agreement. The approach has been termed 'black-box' to denote that service providers (contracted by the DWP) are able to design service provision as they see fit, which stands in stark contrast to the former Pathways to Work and the Flexible New Deal that were characterized by over-specified regulations for providers according to the DWP (nd b). Therefore the Work Programme implies a step towards increasing discretion in service delivery. In the words of the Minister for Welfare Reform, the "black box nature of the Work Programme means providers are completely free to design the support they offer in order to maximise success" (Freud 2011). It is argued that this flexibility will allow provision to account for local factors and individuals' needs with more personalization and tailor-made services. Also the Work Programme tendering process aimed at encouraging a supply chain that was dynamic, evolving and adaptive to labour market and clients' needs by requiring that each applicant 
presented two types of subcontractors (DWP 2011, 2014) - Tier 1 subcontractors (who generally deliver client support from end-to-end) and/or Tier 2 subcontractors (delivering specialist services to clients with complex barriers to employment, often as one-off suppliers). As there are few further substantial requirements in relation to subcontracting, and also due to the lack of up-to-date data in this regard, it is difficult to ascertain the level and nature of supply chains. It is also difficult to ascertain if the number and type of subcontractors mentioned in the regional-level bidding document matches the current local-level supply chain.

Following Ehrler's (2012) typology, these new features of the Work Programme can be characterized as 'business' type New Public Management governance that is distinguished by high performance measures, high steering by contracts, and high operational level discretion (Fuertes and McQuaid 2013c). The increased marketization of labour market services in the UK and the new governance characteristic described above have important implications for the coordination of policies and key stakeholders at the implementation level, as our findings demonstrate.

\subsection{Research design}

To find out how the UK's activation approach and governance model affects the provision of services to the long-term unemployed, case studies were conducted in three localities across the UK (Yin, 2014). These urban localities were chosen due to their different administrative context and economic performance. Firstly, Cardiff and Edinburgh are capitals of the devolved 
administrations of Wales and Scotland. Although both have an additional governmental layer compared to the third locality, Newcastle in England, their administrative settlements are not identical. The three cities were chosen as they covered three of the nations in Great Britain (Scotland, Wales, and England), had similar populations, and were representative of different regional economic performances (best-, average- and under-performing, respectively). Economic performance was measured in terms of three variables (labour force participation rate, unemployment rate, and the regional GDP) ${ }^{3}$ compared to the UK average. Semi-structured interviews were conducted in each locality. Sections 5.4 and 5.5 present our findings from the empirical data collected via the interviews as well as a document analysis.

Section 5.4 focuses on the inter-organizational coordination of local activation policies at a meso-level of analysis. The section draws mainly on interviews with senior staff in organizations involved in the development and implementation of activation policy at the local level. Our selection of participants followed a two-fold approach: first, based on the document analysis a core set of organizations relevant for policy development and implementation were approached; second, relevant local actors were identified through a snowballing technique. Care was taken to interview a wide range of actors within each case study to ensure that different opinions and experiences would be gathered. A total of 66 interviews were conducted (21 in Edinburgh, 20 in Cardiff and 25 in Newcastle). All interviews were face-to-face, lasted between 45 minutes and two hours, were recorded (except four), and were transcribed or 
partly transcribed. Interviews were analysed using NVivo in Edinburgh and thematic matrixes in Cardiff and Newcastle (Braun and Clarke 2006).

Section 5.5 focuses on how the governance of activation affects the individual level and specifically the practices of street-level bureaucrats as the last actor in the service delivery chain. The section draws on semi-structured interviews in a single (anonymous) organization in one locality in the UK, which deliver services mainly to the long-term unemployed as a Work Programme provider. The organization studied requested anonymity due to concerns over intellectual property and commercial confidentiality. Anonymity has, to some extent, reduced the detail and richness of the information presented in this chapter. Eight advisors and nine clients were interviewed. All the advisor interviews and seven client interviews were pre-arranged by the office manager. Interviews were conducted during three days. The interviews focused on the interviewees' recollection of activities and actions in their daily work (i.e. their discourse on those activities); on a few occasions, non-participant observation took place.

\subsection{Co-ordination of services at the local level}

Long-term unemployed individuals often have complex and multiple needs that hinder them from entering the labour market. As a result, activation policies targeted at vulnerable groups require greater consideration of various barriers to working, and more holistic and coordinated services, if activation is going to be effective. This chapter considers the role of governance and local actors in achieving coordinated and tailor-made service delivery. Our main focus lies on 
the Work Programme for the long-term unemployed and some other target groups, but also on the wider governance context in which it is embedded. Our arguments in this section are based on interviews with administrative actors (such as national, regional and local government officials and agencies) and public, private or third-sector provider organizations in the various policy areas that we outlined as relevant to activation (social assistance, health, childcare, education, housing and economic development). In staying within the terminology set by Chapter 2, we refer to coordination among multiple policy areas as 'multidimensional' coordination; coordination among public, private and/or third-sector actors as 'multi-stakeholder' coordination; and coordination among different governance levels as 'multilevel' coordination. Our hypothesis is that local coordination will be constrained by the national governance of activation in the UK; however, we also expect that local authorities and agencies will use the available discretion to either foster or hinder coordination depending on their political interests and strategy.

\section{Multilevel coordination: Parallel governance universes}

Due to the centralized labour market policy governance in the UK, coordination among various local actors in the activation domain (e.g. Jobcentre Plus, external contractors, the local government, agencies) is often low, although it occurs around specific initiatives. A major issue identified by participants is the limited discretion and influence that officials, including local officials of UK bodies, have over the level and use of resources. 
You can get partners sitting in a room talking to each other about what they would like to do, when the reality is that they have got no resources to do anything, because the power lies elsewhere. (Managing Director of a private sector organization)

In the three cities, local strategies developed by local authorities to tackle unemployment differ but the participants stressed that local strategies are considerably constrained by national UK policy and funding, even where local actors are specifically tasked with developing their own approaches.

Also with regard to service priorities, local-level policies tend to align themselves to UK policies through local actors voluntarily adapting their strategies, initiatives and target groups to UK policy in order to avoid duplication and achieve some complementarity (the latter is also a finding from Lindsay and McQuaid 2008). Our participants reported that national and local administrators come together in voluntary forums, boards, and similar forms of coordination, but rigid central procedures, lacking discretion at the managerial level in UK bodies such as Jobcentre Plus and inflexible funding streams of both UK and local bodies often stifle effective collaboration.

\footnotetext{
Jobcentre Plus as an organization, they have their own drivers, and ... Jobcentre Plus district managers will sit with us and agree with us one thing and mean it. And sometimes that just changes, and they said 'I am really sorry but we can't do that anymore', that is part of the difficulties of working, or trying to align national [UK] drivers and local drivers. (Director of a local government agency)
}

In our interviews, we encountered more mature examples of collaboration and co-production, but these were usually restricted to areas where national UK policy is not prescriptive (e.g. employer engagement). Two illustrative examples include the Job Match Initiative in Cardiff which brings together the UK 
Jobcentre Plus with the Welsh Education Department and employers to achieve a match between the skill needs of employers and the 'skills framework' incorporated into the Welsh Baccalaureate; or the Employer Offer in Edinburgh which ensures that stakeholders (such as Jobcentre Plus, the Capital City Partnership and the City of Edinburgh Council) work together to avoid a duplication of specific activation measures (Fuertes and McQuaid 2013a). However, the UK government's recent introduction of the Flexible Support Fund for Jobcentre Plus districts could potentially enable more efficient cooperation and co-production between Jobcentre Plus and other local agencies.

Also with regard to employment policies and measures that are contracted out, coordination between external contractors or between those contractors and local government, agencies and other providers tends to be limited. We refer to the Work Programme as a case in point, although it is slightly different from other initiatives because although the prime contractors are not considered administrative actors, they are neither mere service providers. Due to the degree of freedom that prime contractors have in the development of policy content, they can be considered an integral part of the policy implementation chain. In fact, the institutional flexibility that the primes are afforded in designing service delivery would even predestine them to act as brokers of coordination between national and local actors, policy areas and service providers. According to the Department for Work and Pensions (2012), "encourag[ing] Work Programme providers to form partnerships with other organisations" had been one of the aims behind the 'black-box' governance approach. Nevertheless, such coordination does not appear in our case studies. 
While prime contractors are sometimes present in boards or working groups, their role is more one of information sharing rather than facilitating collaboration or co-production. Hence, according to our findings, marketization and businesstype New Public Management has not fostered an increased coordination of activation services at the local level. However, coordination of national provision with local strategies may occur in instances of marketized service provision, where such coordination is a required factor in implementation (e.g. see Green and Orton 2009).

In two of the case studies, Cardiff and Edinburgh, there is an additional administrative level that has to be taken into consideration, i.e. the Scottish and Welsh governments (devolved administrations). Local actors are influenced by both the national and the devolved government, the latter also having an impact on the relationship between the UK level and local actors. This intermediating role of regional governments is one of the reasons for the stark lack of coordination between Work Programme providers and local actors. What is more, the duality of service provision (centralized and devolved) has the effect that Work Programme participants may be unable to access provisions that are funded by the devolved and local administrations, for instance in the area of skill training. We found this in both of the devolved regions where we conducted interviews (with some exceptions in Wales). According to our respondents, the reasons for the decision taken by the devolved administrations to create an institutional split between Work Programme services and public services at the regional/local level are complex, ranging from: administrative pragmatism (devolved governments seeking to avoid a double funding of services or 
subsidizing national policy or subsidizing large private prime contractors); different activation and contractualization models (with implications for instruments, the pace of interventions and the use of service providers); and different political ideologies and strategies.

The [UK] government chose to award the contracts for the Work Programme to private sector providers and some public bodies don't feel that they want to provide programmes that would help people get jobs and therefore a profit being made by private sector providers. (Chief Executive of a third sector organization)

\section{Multidimensional and multi-stakeholder coordination: some coordination between "silos" and providers}

Beside different funding channels and governance modes between the public and privatized arms of employment service provision in the UK, an additional barrier to service integration at the local level lies in split responsibilities between policy areas, as represented by different departments at the local, regional and/or national level. These institutional rifts across service areas manifest themselves in functional specializations, rigid funding channels, and diverse policy objectives in each area. This has given rise to a 'siloization' or fragmentation of service delivery even within single organizations. As mentioned in Chapter 2, different ways out of the fragmentation of services can be thought of: central coordination, organizational integration, and decentralized collaboration. In our local case studies in the UK, however, non-coordinated policy fields emerge as the norm (although considerable cooperation does take place at the regional level). As in the area of multi-stakeholder coordination, there are occasions in which different policy fields come together in the framework of locally specific initiatives, such as forums, boards, or working 
groups. Examples are the 'Youth Engagement Board' in Cardiff that brings together different council departments and other stakeholders to plan a strategy for integrated service delivery; and the 'cross-partners panel' of the Economic Development Department of the City of Edinburgh Council which also brings different departments together. However, in practice, the actualized level of coordination depends on the specific board and is generally rather low. Thus, in the two examples mentioned above, the stated aim of the department-crossing initiatives was to avoid duplication and complement other initiatives rather than to collaborate.

It's too easy to spend a lot of time at co-ordination meetings that are really not about coordinating, they're just about sharing, discussing things and sharing views, which is fine for a small part of your time but not too much. (Chief Executive of a third sector organization)

There are a few instances of departmental mergers in our case studies, such as the City of Edinburgh Council's decision to merge a number of services and departments into the Economic Development Department which was also given the lead on employability issues; or initiatives that involve different departments, such as 'Families First' in Cardiff that involves the departments of Education, and Children and Families. However, minor convergence or the alignment of policy strategies via forums and working groups seems to be the coordination 'norm' at the local level in the UK.

We also found that in each city, relations between policy areas (with competences at the sub-national level) vary. For example, Scottish Community Planning Partnerships (in which relevant organizations are required to participate by the Scottish Government) bring together public officials from 
sectors such as health, housing, employability etc. The official goal of Community Planning is to improve public services, link up initiatives and partnerships in the local authority area, and align national priorities with those at regional, local and neighbourhood levels. While according to participants this form of formal coordination is far from perfect, it seems to effectively create a forum for policy fields to come together and sometimes to co-produce services. In Wales and Newcastle, no such community forums exist but organizations from different service areas are brought together by different partnerships such as the 'Cardiff Partnership Board' that includes key public and voluntary services, and the 'Economy, Work, Skills and Learning Partnership' in Newcastle that brings together private, public and third sector stakeholders and their respective service offers.

Our local case studies also show little coordination between local actors and the Work Programme providers, beyond limited sub-contracting arrangements that usually imply local actors providing services but having no influence on the implementation of the Work Programme. This mirror the findings of Newton et al. (2012) and the National Audit Office (2014) who ascribed the low use of 'paid-for spot providers' by the primes either to low numbers of participants with specialist needs (which is unlikely in the light of our findings) or to providers minimising external costs. Our study also suggests relatively little involvement of Work Programme providers in local coordination forums, with some exceptions such as Cardiff's Employer Engagement and the regional Work Programme Board in Newcastle (stakeholders nevertheless stated that the board is not resourced adequately, has narrow confines and has 
very little influence on the practicalities of the Work Programme). It was hinted by some prime contractors that the financing model of the Work Programme, which is based on cost and the predicted level of outcomes and performance (Mulheim 2011), restricts the sub-contracting of external provisions. However, as will be shown in the next section, lacking external provisions are not compensated by in-house services, either. Instead, we found that service provision focuses mainly on job-search support with limited specialist support. The next section offers more insights on the influence of governance arrangements on the capacity of front-line workers in one Work Programme office to offer coordinated, integrated services to long-term unemployed clients.

\subsection{Front-line staff and local service delivery}

Lipsky (1980) stressed that policy comes most alive in the interaction between front-line workers (or street-level-bureaucrats) and service users. Evans and Harris (2004) add that street-level-bureaucrats have various gradations of freedom in decision-making that vary on a situation-by-situation basis. Hence, when assessing the availability and accessibility of integrated support for service users, it is vital to take the work-floor level into account. One prerequisite for tailor-made and personalized service support is a broad range of service offers that requires coordination either between the responsible agency (such as a prime contractor) and external providers, or between departments within the organization in question. The remainder of this section analyses the availability of integrated services at the front-line of one Work Programme contractor office and explores the influence of governance, in this 
case business-type New Public Management or decentralized market governance, on front-line staff practices.

\section{Constrained discretion, constrained personalization}

The Work Programme has many characteristics of New Public Management governance: it is a contracted-out and marketized service, based on paymentby-results, with clear performance targets and business-like methods of operation. As a result of the 'black-box' approach, the Work Programme can be considered a decentralized type of New Public Management or, as Ehrler (2012) calls it, a business-type New Public Management. There are limited guidelines from the Department for Work and Pensions on service processes, so Work Programme providers are able to independently establish their chosen service delivery model. According to the Department for Work and Pensions (2011), this flexibility afforded to prime contractors aims at achieving personalized services that meet individual and local needs: "The Work Programme provides more personalised back to work support for claimants with the aim of helping them into sustained work".

This is the discourse, but is this the case in practice? In our case study, front-line workers (advisors) stressed the autonomy and flexibility they are afforded in the organization of their day-to-day work and in the support they give to service users (clients). According to advisors, as long as they meet their targets and offer directly employment-related support, they have flexibility in the pace and content of the services offered.

We are encouraged to be flexible and to do what is right by them. (...)You know, as long as we are doing what we need to do to hit our targets, or we can show that we are doing 
the right thing for the client, we are pretty much left to do whatever we want, within reason. But if I had a client who I thought okay if I spend a day out with them handing out CVs they will get the job, my boss would probably say yes that's okay, you can do that. (Work Programme Advisor)

Interviewees described a typical 'expected' working day in which they arrange 30 minutes meetings with approximately 15 clients, of which 12 or 13 turn up. Advisors' caseloads range from around 80 clients for those dealing with clients classified as 'closer to the labour market' to around 250 clients for advisors with clients that are 'further away from the labour market'. The latter are generally more disadvantaged and have a substantial barrier or a range of barriers to work. The targets that advisors have to achieve are around seven or eight joboutcomes per month and of those around 75-90 per cent sustainability after 13 and 26 weeks (participants were unable to remember with accuracy their sustainability targets). Advisors' daily work consists mainly of meeting clients. In these meetings, they discuss what the client has been doing in terms of job search or other activities (normally a number of activities that were agreed in the previous meeting), the client's current personal and household situation (more personal questions), and the activities to be undertaken by the next meeting. Activities range from job-search to other activities such as attending workshops; however, the majority of the activities are job-focused.

Although advisors feel they are afforded autonomy and flexibility in their role, it could be argued that this is counteracted by their heavy caseloads, their Key Performance Indicators, and the apparent similarity in the support offered, which is primarily focused on limited and intensive job-search and job-brokering activities. This in practice limits the discretion of front-line staff to affect the 
implementation of integrated services (Evans and Harris 2004). Service users corroborated this emphasis on a limited set of job-related activities.

When I first see [my caseworker], she'll ask how I'm doing, and anything we've talked about before. (...) Then she'll immediately tell me about any vacancies that came up, the ones on the board. (...) They give me all the information, like how to apply, email, what hours, what they need, and then what they think I should do, their sort of view on it. But it's still up to you what you do, it's just what they think. (Work Programme service user)

This produces what we term 'constrained discretion' or what Toerien et al. (2013) termed 'procedural personalisation'. This concept allows for both the limited discretion of service content in practice, and for advisors' and clients' accounts of personalized interactions that are one-to-one, include discussions of personal issues, and afford clients some voice in the pace and (limited) type of support.

\section{Limited coordination of services}

Support given by participant front-line workers to clients consists mostly of jobfocused assistance. It also includes listening, and adapting the job-focused assistance to a client's circumstances that ultimately are barriers to participating in the labour market. This is partly necessary in order to achieve sustained joboutcomes (which are one of the Key Performance Indicators in the programme). Arguably, sustainability requires more careful consideration of, and ultimately tackling, individual and household barriers to employment.

In our case study, the pace and content of support varies to some extent according to clients' classifications as either 'further from' or 'closer to' the labour market. There is a typical path of support for each of these two groups; 
however, it is not linear and clients can access different support at different times. The latter group experience more intensive job-focused support, with more regular visits with their advisor and more job-activities between meetings. The group classified as further away from the labour market is more often referred to in-house activities or specialist out-sourced provision depending on their needs; and the pace of support and job-focused assistance is less intense.

Advisors and clients stress that the support offered in-house and externally is good. However, in-house support consists mostly of job-focused workshops (e.g. interview techniques, using computers, etc.) or deals with very specific issues, such as pain or sleep management. In our case study, the number of organizations involved as subcontractors is very limited compared to the number of local specialist providers. Advisors refer clients to other local services that they could access depending on their needs - here, advisors do have some discretion in the service they suggest (constrained by their Key Performance Indicators, their resources and the local availability of services). However, approaching these organizations is entirely the decision of the client, and access depends on the availability of services and eligibility of clients. Furthermore there is no systematic approach to this type of referrals.

Participants in our case study recognized that advisors and the Programme are unable to deal with the complex needs of most Employment Support Allowance clients, whose numbers they report to have increased substantially since the start of the Work Programme. Analysing the Department for Work and Pensions' statistics on job outcomes for those in Employment Support Allowance (ESA) shows that outcomes for those with disabilities have 
been lower than expected (see National Audit Office 2014: 30). Therefore it can be assumed that the Work Programme is not tackling the barriers to employment of those that have multiple and complex problems.

In a nutshell, according to our front-line case study, the governance model of the Work Programme (i.e. decentralized New Public Management) means that providers' limited resources are targeted to those that will provide the best and quickest return. Quick and short interventions focus on intensive job-search activities, which constitute the majority of support offered by our participants as a result of limited resources (staff and support). This may disadvantage mostly those clients with complex and multiple needs. Our findings seem to challenge the government's intention to achieve integrated and personalized services through the Work Programme. However, it seems to correspond with the government's discursive approach to unemployment, which focuses on the behavioural nature of unemployment (e.g. the 'deserving' poor, including those with clear disabilities, and 'undeserving' poor), and corresponds to labour market activation measures that are short, intensively focused on job search and enforced through sanctions.

\subsection{Concluding remarks}

This chapter investigated the influence on national, regional and local governance arrangements on the provision of integrated employment and social services to the long-term unemployed in the UK. Due to labour market policy being a centralized UK government responsibility, we found similar overall governance forms in all three local case studies. As discussed above, the 
delivery organizations of national labour market policy (whether the Public Employment Service - Jobcentre Plus - or contracted-out providers such as Work Programme providers and their sub-contractors) are independent from sub-national government (i.e. devolved administration governments or local authorities) in terms of competences, resources and accountability. Hence, greater marketization appears to have increased fragmentation among service providers. Some service coordination takes place by the Work Programme prime contractors contracting-out specialist services; however, many subcontractors have found that despite having contracts, they receive far fewer client referrals than expected, in which case service coordination is limited in practice.

Local contexts, through local and devolved government discretion and employability policies, do play a role in the degree of coordination between policy levels, fields and stakeholders, especially when it comes to services provided outside of the Work Programme. Variations in local service delivery coordination were found to be the result of local government institutional creation (e.g. Newcastle Future, Edinburgh's Capital City Partnership); structured forums and working groups; informal relations that bring actors together around specific initiatives; and the usage of discretion by local and devolved administrations on issues indirectly related to employment policy.

There seems to be a general lack of coordination between territorial levels, which impacts significantly on policy-area and stakeholder coordination. In particular, the centralized procedural governance of national labour market policy through the Jobcentre Plus appears to be a barrier towards coordination. 
Although there is often a desire to coordinate, actors are often limited in their ability to collaborate effectively due to bureaucratic constraints in terms of objectives, regulations and resources, and the reluctance of Jobcentre Plus to give up centralized control and allow more local flexibility (although this has the advantage that similar services are available consistently across the whole of the UK). Local actors are left to develop policies around national UK provision in order to avoid duplication or to fill 'gaps', or to seek coordination where national policy is not prescriptive. However, this fragmentation and disconnection can create confusion, duplication, inefficiencies and gaps in provision that often become apparent during policy implementation.

The coordination of policy fields and stakeholders varies between localities in terms of intensity and inclusiveness. Market-based governance is used by all three local authorities with regards to employability-related services, in some cases bringing together actors from different policy fields. However, the degree of coordination depends partly on the local strategy. Coordination also takes place through projects and funding, but is often limited in time and scope. Participants mentioned that coordination could be achieved if actors within and across policy fields shared the same final objective (e.g. employment as the final aim), but that to attain this would be difficult due to professional boundaries (with regards to aims and resources) as well as organizational protectionism.

Considering the specific national UK policy for the long-term unemployed, the Work Programme, we found that the innovative elements of this marketbased initiative have not achieved comprehensive multilevel coordination, especially in Edinburgh and Cardiff. In particular, the Work Programme's 
funding model has not resulted in multidimensional coordination and has only accomplished limited principal-agent (market-based) stakeholder coordination. There has also been a deliberate lack of coordination in terms of allowing Work Programme clients to use programmes funded by the devolved governments due to pragmatism, different approaches to activation, and different political ideologies. The lack of coordination means that Work Programme service users are sometimes unable to access local employability services. This, together with the limited Work Programme provision, affects the support that unemployed individuals mandated to the Programme are receiving.

Although individual street-level advisors enjoy flexibility and autonomy in allocating services, their discretion is constrained by practical factors such as their caseload, their Key Performance Indicators and the services available inhouse and from external organizations. These factors are part of the organizational context which is influenced by the policy and governance background. In practice, the smaller the range of available services, the greater the standardization of support - irrespective of the formal discretionary space front-line workers may have. Standardized support does not allow a personalization of provision, which requires the possibility of accessing a wide range of services if the front-line worker should decide they are necessary. The aim of the policy and operation of the Work Programme, including its financial model, are both underpinned by New Public Management and market-based governance which, we argue, restricts a coordination of services unless established guidelines, a clear strategy, and/or incentives are in place. The Work Programme also operates within existing governance barriers to 
coordination between public stakeholders and administrative levels; this can result either in local provision gaps or in a duplication of services situated at different administrative levels.

More research into how national activation policies and associated programmes are implemented and co-ordinated at the local level is needed. The Work Programme is an interesting case study as, while being only a twoyear programme for many participants, its scale and scope makes it an important activation policy in the UK. It is also important because, while it follows previous welfare-to-work policy and governance characteristics, it introduces novel governance elements that could signal an opportunity to achieving coordination, personalization and more holistic services. As McQuaid and Fuertes (2014) have suggested, the Work Programme has the potential to move from a 'work-first' to a more 'career-first' system emphasizing long-term, sustainable employment with progression in terms of employment conditions, training, pay and/or longer term career development. However, opportunities to learn from positive and negative practices in such programmes are limited due to commercial providers requiring anonymity under intellectual property and commercial confidentiality.

\section{References}

Braun, V. and V. Clarke (2006), 'Using thematic analysis in psychology', Qualitative Research in Psychology, 3 (2), 77-101.

Considine, M. and J.M. Lewis (2003), 'Bureaucracy, network, or enterprise? Comparing models of governance in Australia, Britain, the Netherlands, and New Zealand', Public Administration Review, 63 (2), 131-140. 
Davies, S. (2010), 'Outsourcing and the voluntary sector: A review of the evolving policy landscape', in I. Cunningham and P. James (eds.), Voluntary organizations and public service delivery, London: Routledge, pp. 15-36.

DWP (2011), Work Programme: Equality Impact Assessment, accessed 28 April 2015 at www.gov.uk/government/uploads/system/uploads/attachment_data/file/220250/eiawork-programme.pdf.

DWP (2012), The Work Programme, accessed 28 April 2015 at www.dwp.gov.uk/supplyingdwp/what-we-buy/welfare-to-work-services/provider-guidance/work-programmeprovider.shtml.

DWP (2014), Work Programme: DWP provider guidance, accessed 31 July 2014 at www.gov.uk/government/publications/work-programme-dwp-provider-guidance.

DWP (nd a) website (2007), Framework generic provider guidance, accessed 5 May 2013 at www.dwp.gov.uk/supplying-dwp/what-we-buy/welfare-to-work-services/framework-forthe-provision/.

DWP (nd b) website (2012), Minimum service delivery by prime provider, accessed April 2012 at www.dwp.gov.uk/docs/provider-minimum-service-delivery.pdf.

Ehrler, F. (2012), 'New public governance and activation', International Journal of Sociology and Social Policy, 32(5/6), 327-339.

Eichhorst, W., O. Kaufmann and R. Konle-Seidl (eds.) (2008), Bringing the jobless into work?: experiences with activation schemes in Europe and the US, Berlin and Heidelberg: Springer.

Evans, T. and J. Harris (2004), 'Street-level bureaucracy, social work and the (exaggerated) death of discretion', British Journal of Social Work, 34 (6), 871-895.

Finn, D. (2000), 'Welfare to work: the local dimension', Journal of European Social Policy, 10 (1), 43-57. 
Freud, D. (2011), 'Health and wellbeing. A speech by Lord David Freud, Minister for Welfare Reform', Speech presented at the Govnet Health and Wellbeing Conference, Department for Work and Pensions, 6 October.

Fuertes, V., B. Jantz, T. Klenk and R. McQuaid (2014), 'Between cooperation and competition: the organization of employment service delivery in the United Kingdom and Germany', International Journal of Social Welfare, 23 (S1), S71-S86.

Fuertes, V. and R. McQuaid (2013a), 'The local governance of social cohesion: United Kingdom country analysis', LOCALISE WP4 National Report, unpublished.

Fuertes, V. and R. McQuaid (2013b), 'The local governance of social cohesion in Europe: international comparison', LOCALISE WP4 Comparative Report, available at http://www.localise-research.eu/wp-content/uploads/2013/07/D4.7-INTERNATIONALComparative-Report.pdf (accessed 2015-06-30).

Fuertes, V. and R. McQuaid (2013c), 'The Work Programme: a new public governance policy or a continuation of new public management?' Paper presented at the PART-WEL Conference 'Participatory local welfare, citizenship and third sector organizations: What is at stake?', Pisa, Italy, 31 Jan. - 1 Feb. 2013.

Green, A. and M. Orton (2009), 'The integration of activation policy at sub-national level: a case study of the City Strategy initiative in an English sub-region', International Journal of Sociology and Social Policy, 29 (11/12), 612-623.

Hasluck, C. and A.E. Green (eds.) (2007), What works for whom?: a review of evidence and meta-analysis for the DWP, London: DWP (No. 407), Corporate Document Services.

House of Commons Work and Pensions Committee (2007), The Government's Employment Strategy - Third report of session 2006-07. House of Commons 21 February 2007, London: The Stationery Office Limited. 
Hudson, M., J. Phillips, K. Ray, S. Vegeris and R. Davidson (2010), The influence of outcomebased contracting on Provider-led Pathways to Work (Vol. 638), Norwich: Department for Work and Pensions.

Karjalainen, V. (2010), 'Actors, scaling and governance in activation policy', in Y. Kazepov (ed.), Rescaling social policies: towards multilevel governance in Europe, Surrey and Burlington: Ashgate, pp. 139-174.

Kazepov, Y. (ed.) (2010), Rescaling social policies: Towards multilevel governance in Europe, Surrey and Burlington: Ashgate.

Künzel, S. (2012), 'The local dimension of active inclusion policy', Journal of European Social Policy, 22 (1), 3-16.

Lindsay, C. and M. Dutton (2012), 'Promoting healthy routes back to work? Boundary spanning health professionals and employability programmes in Great Britain', Social Policy \& Administration, 46 (5), 509-525.

Lindsay, C. and R.W. McQuaid (2008), 'Inter-agency co-operation in activation: Comparing experiences in three vanguard 'active' welfare states', Social Policy \& Society, 7 (3), 353-365

Lipsky, M. (ed.) (1980), Street-level bureaucracy: Dilemmas of the individual in public services, New York: Russell Sage.

McQuaid, R.W. (2010), 'Theory of Organizational Partnerships - partnership advantages, disadvantages and success factors', in S.P. Osborne (ed.), The New Public Governance: Emerging perspectives on the theory and practice of public governance, London: Routledge, pp. 125-146.

McQuaid, R. and V. Fuertes (2014), 'Sustainable integration of the long term unemployed: From Work First to Career First', in C. Larsen, S. Rand, J. Schmid and R. Keil (eds.), 
Sustainable economy and sustainable employment, Munich: Rainer Hampp Verlag, pp. 359-373.

McQuaid, R.W. and C. Lindsay (2005), 'The concept of employability', Urban Studies, 42(2), 197-219.

Mulheim, I. (2011), Will the Work Programme Work? Examining the future viability of the Work Programme, London: Social Market Foundation.

National Audit Office (2014), The Work Programme, accessed July 2014 at www.nao.org.uk/wpcontent/uploads/2014/07/The-work-programme.pdf

National Audit Office (2006), Jobcentre Plus: Delivering effective services through Personal Advisers, London: Stationery Office Limited.

Newton, B., N. Meager, C. Bertram, A. Corden, A. George, M. Lalani and K. Weston (2012), 'Work Programme evaluation: Findings from the first phase of qualitative research on programme delivery (No. 821)', London: Department for Work and Pensions.

Oakley, M. (2014), 'Independent review of the operation of Jobseeker's Allowance sanctions validated by the Jobseekers Act 2013', accessed 28 April 2015 at https://www.gov.uk/government/uploads/system/uploads/attachment_data/file/335144/js a-sanctions-independent-review.pdf

Rhodes, R.A.W. (ed.) (1997), Understanding governance. Policy networks, governance, reflexivity and accountability, Milton Keynes: Open University Press.

Saikku, P. and V. Karjalainen (2012), 'Network governance in activation policy - health care as an emergent partner', International Journal of Sociology and Social Policy, 32(5/6), 299-311.

Stafford, B. and Kellard, K. (2007), 'Reforming the public sector: Personalised activation services in the UK', in R. van Berkel and B. Valkenburg (eds.), Making it personal: Individualising activation services in the EU, Bristol: Policy Press, pp. 127-148. 
Stewart, M. (2005), 'Collaboration in multi-actor governance', in M. Haus, H. Heinelt and M. Stewart (eds.), Urban governance and democracy: Leadership and community, London and New York: Routledge, pp. 149-167.

Taylor-Gooby, P., T. Larsen and J. Kananen (2004), 'Market means and welfare ends: the UK welfare state experiment', Journal of Social Policy, 33 (4), 573-592.

Toerien, M., R. Sainsbury, P. Drew and A. Irvine (2013), 'Putting personalisation into practice: work-focused interviews in Jobcentre Plus', Journal of Social Policy, 42 (2), 309-327.

Van Berkel, R. and V. Borghi (2008), 'Introduction: The governance of activation', Social Policy and Society, 7 (3), 331-340.

Van Berkel, R., W. De Graaf and T. Sirovátka (2012), 'Governance of activation policies in Europe', International Journal of Sociology and Social Policy, 32 (5), 260-272.

Vegeris, S., K. Vowden, C. Bertram, R. Davidson, L. Durante, M. Hudson and D. Smeaton (2010), 'Jobseekers regime and flexible new deal evaluation: A report on qualitative research findings', DWP Research Report No 706.

Yin, R. K. (2014), Case study research: Design and methods, Los Angeles: Sage Publications.

Zimmermann, K., P. Aurich, P. Graziano and V. Fuertes (2014), 'Local worlds of marketization: Employment policies in Germany, Italy and the United Kingdom compared', Social Policy \& Administration, 48 (2), 127-148.

Zimmermann, K. and Fuertes, V. (2014). Employment policy implementation mechanisms in the European Union, the United Kingdom and Germany. Employment Working Paper No. 160. Geneva: International Labour Office, Employment Policy Department. 
1 Source: http://tabulation-tool.dwp.gov.uk/100pc/tabtool.html

2 Non-compliance with rules (such as refusing a reasonable offer of employment or leaving a job voluntarily) will bring losses of benefits for 13 weeks, 26 weeks and 3 years for the first, second and third failures, respectively. Those sanctioned could apply for special "hardship payments" administered by local authorities. Full details of regulation can be found in DWP (2012).

3 The three variables used are: the labour force participation rates (in $\%$ of the annual average population (from 15 to 64 years, 2008); the total unemployment rate (in \% of the labour force, 2008); the regional gross domestic product (purchasing power parities per inhabitant, 2008). 